\title{
Pengendalian Motor Servo Yang Terintegrasi Dengan Webcam Berbasis Internet Dan Arduino
}

\author{
Rinaldy $^{1}$, Risa Farrid Christianti ${ }^{2}$, Didi Supriyadi ${ }^{3}$ \\ Preogram Studi Diploma III Teknik Telekomunikasi \\ 1,2,3 Sekolah Tinggi Teknologi Telematika Telkom Purwokerto \\ Jl. D.I.Panjaitan no.128 Purwokerto \\ ${ }^{1}$ Rinaldynaldy@yahoo.com, ${ }^{2}$ risa@st3telkom.ac.id, ${ }^{3}$ didisupriyadi@st3telkom.ac.id
}

\begin{abstract}
Seperti halnya internet, yang merupakan suatu jaringan global yang dapat mengkomunikasikan satu komputer dengan komputer yang lain, di manapun lokasi komputer tersebut berada, maka dapat diaplikasikan suatu proses pengendalian jarak jauh, dengan menggunakan mikrokontroler, sedemikian hingga objek yang bergerak mencurigakan dapat dimonitor oleh webcam, yang dapat digerakkan secara dinamis oleh pengguna. Hal ini diaplikasikan dalam sistem keamanan di dalam rumah pada saat rumah ditinggal jauh oleh pemiliknya. Untuk menunjang sistem keamanan, perlu adanya pemantauan yang dilakukan demi menghindari kasus pencurian. Pengguna dapat melihat tampilan camera dari software yang terintegrasi dengan webcam, selain itu pengguna dapat mengendalikan pergerakan kamera dengan tombol-tombol yang tersedia pada tampilan website yang berbasis HTML. Dalam penelitian ini alat kendali motor servo dapat bekerja dengan baik, dengan simpangan sudut mendekati $180^{\circ}$.
\end{abstract}

Kata kunci : Webcam, Arduino, Website, HTML, Internet, arduino ethernet shields.

\section{PENDAHULUAN}

Internet merupakan media yang dapat menyampaikan informasi melalui jarak jauh, internet dapat dimanfaatkan dalam proses pembuatan alat pengendalian motor servo yang terintegrasi dengan webcam berbasis arduino. Alat pengendalian motor servo yang terintegrasi dengan webcam berbasis internet dan arduino merupakan perangkat monitoring yang memiliki manfaat utama untuk menambahkan rasa aman bagi pengguna alat ini, untuk itu alat ini harus dapat dikendalikan melalui jarak jauh, yang memanfaatkan media internet.

Dalam penelitian ini akan dijelaskan mengenai aplikasi pengendalian motor servo melalui jarak jauh melalui internet untuk meningkatkan keamanan di rumah, dengan harga yang relatif terjangkau. dengan memanfaatkan mikrokontroler Arduino sebagai pengendalinya.

\section{DASAR TEORI}

\section{A. Arduino Uno}

Arduino adalah sebuah platform elektronika open source yang berdasarkan fleksibilitas, mudah dalam menggunankan perangkat keras dan perangkat lunak. Alat ini ditujukan untuk seniman, desainer, dan orang yang tertarik untuk menciptakan objek interaktif.

Arduino uno sangat mudah untuk digunakan, tanpa melakukan konfigurasi apapun, arduino uno sudah dapat langsung digunakan, dengan menyambungkan ke sebuah komputer melalui kabel USB. Kabel USB juga akan mengalirkan arus DC 5 Volt untuk Arduino.

Arduino Uno merupakan papan mikrokontroler yang berdasarkan Atmega328. Arduino Uno memiliki 14 pin digital input dan output, 6 pin input analog, 16 $\mathrm{MHz}$ ceramic resonator, sebuah koneksi Universal Serial Bus, sebuah Power Jack, sebuah ICSP header, dan tombol reset. semua ini diperlukan utuk mendukung mikrokontroler, dengan mudah untuk menghubungkan ke sebuah computer dengan kabel $U S B$ atau tegangan $A C$-to-DC dengan menggunakan adapter atau battery untuk menjalankan Arduino Uno. Arduino Uno merupakan board processing yang berbeda dari semua board processing, dikarenakan Arduino Uno tidak menggunakan FTDI USB-to-serial drive chip. Arduino Uno memiliki gambar (gambar 1) dan spesifikasi sebagai berikut:
1. Mikrokontroller : ATmega328
2. Operating Volatge : $5 \mathrm{~V}$
3. Input Volatge : 7-12 V
4. Input Voltage Limit : $6-20 \mathrm{~V}$
5. Digital I/O Pins : 14 (of which 6 provide PWM output)
6. Analog Input Pins : 6
7. DC Current Per I/O Pin: $40 \mathrm{~mA}$
8. DC Current for $3.3 \mathrm{~V}$ Pin: $50 \mathrm{~mA}$
9. Flash Memory: $32 \mathrm{~KB}$ (ATmega328)
10. SRAM : $2 \mathrm{~KB}$ (ATmega328)
11. EEPROM : $1 \mathrm{~KB}$ (ATmega328)
12. Clock Speed : $16 \mathrm{MHz}$ 


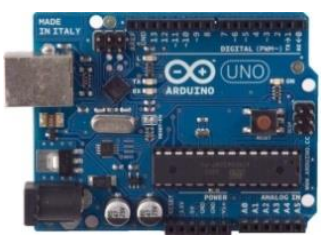

Gambar 1. Arduino Uno ${ }^{[10]}$

\section{B. Arduino Ethernet Shields}

Arduino Ethernet Shields (gambar 2) merupakan papan arduino yang berfungsi untuk menghubungkan papan arduino dengan internet. Menghubungkan arduino ke internet hanya dibutuhkan kabel RJ45. Dengan sedikit petunjuk sederhana arduino Ethernet shields, sudah dapat dihubungkan dengan internet. Setiap elemen pada arduino ethernet shields bersifat open source. Dengan open source arduino eternet shields dapat dipelajari dengan baik, dengan memanfaatkan desain dari board arduino ethernet shields. Arduino Ethernet Shields menggunakan chip Wiznet5100 yang menyediakan sebuah jaringan dengan kemampuan TCP dan UDP. Hal ini memungkinkan untuk empat soket terhubung secara simultan. Dengan menggunakan Ethernet Library untuk menulis sketsa yang menghubungkan ke internet dengan menggunakan Shields. Arduino Ethernet Shields menghubungkan Arduino dengan menggunakan long wire-wrap headers yang diperpanjang melalui shields. Hal ini membuat kaki kaki pada arduino ethernet shields dan arduino tetap utuh dengan cara menumpukkan arduino ethernet shields diatas papan arduino. Arduino Ethernet Shields menguhungkan arduino ke internet hanya dalam hitungan menit. Arduino ethernet shields memiliki sambungan RJ45 standar, dengan trafo garis terpadu dan power over ethernet diaktifkan. Pada arduino ethernet shields terdapat slot micro SD, Micro- SD dapat digunakan untuk menyimpan file yang dilayani melalui jaringan. Slot ini juga sudah kompatibel dengan arduino uno dan mega. Arduino berkomunikasi dengan baik antara W5100 dan micro$S D$, dengan menggunakan SPI bus melalui header ICSP. W5100 dan micro-SD tidak dapat dioperasikan secara bersamaan dalam satu waktu, dikarenakan W5100 dan micro-SD menggunakan satu penghubung yaitu SPI bus.

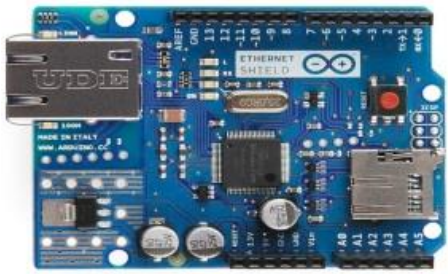

Gambar 2. Arduino Ethernet Shields ${ }^{[10]}$

Arduino Ethernet Shields memiliki beberapa indicator LED sebagai berikut :
1. PWR : menampilkan board dan shields dalam kondisi menyala

2. LINK : menampilkan adanya aliran proses data yang ditandai dengan berkedipnya $L E D$

3. FULLD : menampilkan bahwa jaringan terhubung dengan kondisi full duplex

4. 100M : menampilkan kecepatan jaringan dalam sambungan

5. $R X:$ menampilkan bahwa shields menerima data

6. $T X$ : menampilkan bahwa shields mengirim data

7. COLL : menampilkan bahwa terjadi tabrakan data pada jaringan.

\section{Software Arduino}

Software arduino memiliki tampilan sesuai dengan gambar 3 . Sehubungan dengan pembahasan untuk saat ini software Arduino yang akan digunakan adalah driver dan IDE, walaupun masih ada beberapa software lain yang sangat berguna selama pengembangan Arduino. IDE Arduino adalah software yang sangat canggih ditulis dengan menggunakan Java. IDE Arduino terdiri dari:

1. Editor program, sebuah window yang memungkinkan pengguna menulis dan mengedit program dalam bahasa Processing.

2. Compiler, sebuah modul yang mengubah kode program (bahasa Processing) menjadi kode biner. Bagaimanapun sebuah microcontroller tidak akan bisa memahami bahasa Processing. Yang bisa dipahami oleh microcontroller adalah kode biner. Itulah sebabnya compiler diperlukan dalam hal ini.

3. Uploader, sebuah modul yang memuat kode biner dari komputer ke dalam memory di dalam papan Arduino.

IDE dibagi menjadi tiga bagian, toolbar di bagian atas, kode dan jendela sketsa di tengah, dan jendela pesan di bagian bawah. Toolbar itu sendiri terdiri dari tujuh tombol.

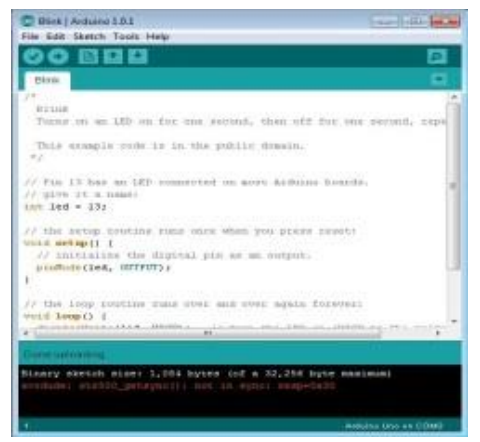

Gambar 3. IDE Arduino ${ }^{[10]}$

\section{Motor Servo}

Motor Servo merupakan motor yang mampu bekerja secara dua arah, motor servo bekerja dengan sistem closed feedback dimana posisi dari motor servo akan diinformasikan kembali ke rangkaian kontrol yang ada didalam motor servo. Motor servo terdiri dari 
sebuah motor, rangkaian gear, potensiometer, serta rangkaian control. Potensiometer pada motor servo berfungsi sebagai penentu batas sudut dari putaran servo. Motor servo biasanya hanya bergerak mencapai sudut tertentu saja dan tidak secara kontinyu. Namun untuk beberapa keperluan motor servo dapat dimodifikasi bergerak secara kontinyu. Berikut spesifikasi dari motor servo :

1. Memiliki 3 jalur kabel power, ground dan control

2. Sinyal control mengendalikan posisi

3. Operasional dari motor servo dikendalikan oleh pulsa selebar $20 \mathrm{~ms}$

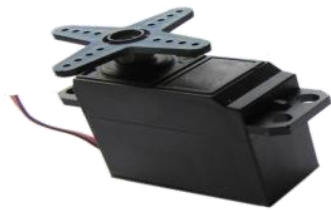

Gambar 4. Motor Servo ${ }^{[6]}$

\section{E. Wi-Fi (Wireless Fidelity)}

$\mathrm{Wi}-\mathrm{Fi}$ merupakan teknologi standart yang memungkinkan koneksi tanpa kabel antara perangkat dengan Local Area Networks. Wi-Fi pada saat ini lebih banyak digunakan untuk mengakses internet.

Tabel 1. Spesifikasi Wi-Fi

\begin{tabular}{|c|c|c|c|}
\hline Spesifikasi & Kecepatan & $\begin{array}{c}\text { Frekuensi } \\
\text { Band }\end{array}$ & $\begin{array}{c}\text { Cocok } \\
\text { Dengan }\end{array}$ \\
\hline $802.11 \mathrm{~b}$ & $11 \mathrm{Mb} / \mathrm{s}$ & $2.4 \mathrm{Ghz}$ & $\mathrm{B}$ \\
\hline $802.11 \mathrm{a}$ & $54 \mathrm{Mb} / \mathrm{s}$ & $5 \mathrm{Ghz}$ & $\mathrm{A}$ \\
\hline $802.11 \mathrm{G}$ & $54 \mathrm{Mb} / \mathrm{s}$ & $2.4 \mathrm{Ghz}$ & $\mathrm{B}, \mathrm{G}$ \\
\hline $802.11 \mathrm{n}$ & $100 \mathrm{Mb} / \mathrm{s}$ & $2.4 \mathrm{Ghz}$ & $\mathrm{B}, \mathrm{G}, \mathrm{N}$ \\
\hline
\end{tabular}

\section{Tipe Jaringan Wi-Fi}

Seperti halnya Ethernet - LAN (jaringan dengan kabel), jaringan Wi-Fi juga dikonfigurasikan ke dalam dua jenis jaringan.

1. Jaringan Peer to Peer/Ad Hoc Wireless LAN

Komputer dapat saling terhubung berdasarkan nama SSID (Service Set Identifier). SSID adalah nama identitas komputer yang memiliki komponen nirkabel.

2. Jaringan Server Based / Wireless Infrastrukture Sistem infrasrtuktur membutuhkan sebuah komponen khusus yang berfungsi sebagai Acces Point.

\section{F. Webcam/IP Camera ${ }^{[11]}$}

Webcam atau web camera adalah sebuah kamera video digital kecil yang dihubungkan ke komputer melalui (biasanya) port USB ataupun port COM. Istilah webcam merujuk pada teknologi secara umumnya, sehingga kata web terkadang diganti dengan kata lain yang mendeskripsikan pemandangan yang ditampilkan di kamera, misalnya StreetCam yang memperlihatkan pemandangan jalan. Ada juga
Metrocam yang memperlihatkan pemandangan panorama kota dan pedesaan, TraffiCam yang digunakan untuk memonitor keadaan jalan raya, cuaca dengan Weather Cam, bahkan keadaan gunung berapi dengan VolcanoCam.

Sebuah web camera yang sederhana terdiri dari sebuah lensa standar, dipasang di sebuah papan sirkuit untuk menangkap sinyal gambar; casing (cover), termasuk casing depan dan casing samping untuk menutupi lensa standar dan memiliki sebuah lubang lensa di casing depan yang berguna untuk memasukkan gambar kabel support, yang dibuat dari bahan yang fleksibel, salah satu ujungnya dihubungkan dengan papan sirkuit dan ujung satu lagi memiliki connector, kabel ini dikontrol untuk menyesuaikan ketinggian, arah dan sudut pandang web camera. Sebuah web camera biasanya dilengkapi dengan software, software ini mengambil gambargambar dari kamera digital secara terus menerus ataupun dalam interval waktu tertentu dan menyiarkannya melalui koneksi internet. Ada beberapa metode penyiaran, metode yang paling umum adalah software merubah gambar ke dalam bentuk file JPEG dan menguploadnya ke web server menggunakan File Transfer Protocol (FTP).

Frame rate mengindikasikan jumlah gambar sebuah software dapat ambil dan transfer dalam satu detik. Untuk streaming video, dibutuhkan minimal 15 frame per second (fps) atau idealnya $30 \mathrm{fps}$. Untuk mendapatkan frame rate yang tinggi, dibutuhkan koneksi internet yang tinggi kecepatannya. Sebuah web camera tidak harus selalu terhubung dengan komputer, ada web camera yang memiliki software webcam dan web server bulit-in, sehingga yang diperlukan hanyalah koneksi internet. Web camera seperti ini dinamakan "network camera". Kita juga bisa menghindari penggunaan kabel dengan menggunakan hubungan radio, koneksi Ethernet ataupun $\underline{\mathrm{WiFi}}$.

Penggunaan web camera mencakup video conferencing, internet dating, video messaging, home monitoring, images sharing, video interview, video phone-call, dan banyak hal lain. Pada awalnya, bentuk web camera terbatas pada bentuk-bentuk standar yang hanya terdiri dari lensa dan papan sirkuit serta casing yang biasa. Namun seiring dengan perkembangan teknologi, bentuk web camera pun sudah makin bervariasi dengan fitur-fitur yang makin canggih. Salah satu bentuk web camera yang unik adalah bentuk boneka yang lucu, web camera ini dapat disalahartikan hanya sebagai boneka dan bukan webcam.

Sekarang ini web camera yang ada di pasaran pada umumnya terbagi ke dalam dua tipe: web camera permanen (fixed) dan revolving web camera. Pada web camera permanen terdapat pengapit untuk mengapit lensa standar di posisi yang diinginkan untuk menangkap gambar pengguna. Sedangkan pada revolving web camera terdapat landasan dan lensa standar dipasang di landasan tersebut sehingga dapat 
disesuaikan ke sudut pandang yang terbaik untuk menangkap gambar pengguna.

Dalam penelitian ini digunakan webcam yang berjenis IP camera (gambar 5) dengan merk pabrikan dari Sun Bio. IP Camera merupakan kamera nirkabel yang terintegrasi. IP Camera menggabungkan kamera video dengan konektivitas jaringan web server. Fungsi dasar IP Camera adalah transmisi video jarak jauh pada jaringan dengan menggunakan IP. Gambar maupun video kualitas tinggi dapat ditransmisikan dengan kecepatan 30 fps pada $L A N$ / WAN dengan menggunkan teknologi MJPEG. IP Camera ini berdasarkan standar $T C P / I P$, terdapat web server didalam IP Camera yang mendukung Internet Explorer.

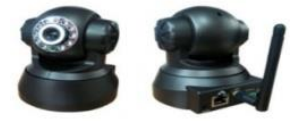

Gambar 5. Web Camera ${ }^{[11]}$

\section{G. HTML (Hyper Text Mark-Up Language)}

HTML dapat dibuat pada sembarang editor, meskipun terdapat program-program khusus, yang dimaksudkan untuk membuat HTML tersebut, adapun program-program editor tersebut adalah Notepad, Wordpad dan lain-lain. Pembuatan teks HTML hampir sama dengan pembuatan teks-teks lainnya seperti pada MS.Word. Pemberian format pada suatu teks dalam sebuah dokumen aan bisa langsung terlihat hasilnya. Berbeda dengan dokumen $H T M L$, formatformat yang diberikan pada suatu teks tidak bisa dilihat langsung hasilnya tetapi harus menggunakan browser untuk dapat melihat hasilnya. Perbedaan mendasar terhadap dokumen-dokumen lainnya yaitu HTML tidak bisa mengandung link / hubungan kebagian lain dari sebuah dokumen atau dokumen lain dari situs web baik dalam server web yang lama ataupun server web lainnya.

Eksistensi dokumen HTML yang menggunakan 3 karakter, awalnya adalah untuk mengakomodasi sistem penamaan yang ada dalam sistem operasi $D O S$. Nama dokumen yang sama tetapi dituliskan dengan case yang berbeda akan dianggap sebagai dokumen yang berbeda, misalnya dokumen .html akan berbeda dengan DOKUMEN.html. Kasus case sensitive akan dijumpai pada dokumen web yang di-hosting didalam server yang berbasi *nix.

\section{PENGUJiAn DAN ANALISA}

\section{A. Tampilan di Monitor}

Pada saat user akan memulai menggunakan alat kendali motor servo ini, maka user akan dihadapkan dengan tampilan yang sudah ditanamkan sebelumnya pada sistem alat kendali motor servo tersebut, yang dibuka melalui browser yang digunakan oleh user. Pada tampilan user akan dihadapkan dengan layout yang cukup sederhana, layout tersebut juga menampilkan informasi derajat perputaran servo, judul dari tampilan alat kendali motor servo tersebut, dan 4 menu utama yang berbentuk tombol perintah.

Tampilan layout menyediakan tampilan yang sederhana dan mudah dimengerti oleh user atau pengguna. Layout ditampilkan apabila user atau pengguna sudah memanggil halaman HTML itu sendiri, melalui web address pada browser. Layout pada alat kendali motor servo berjenis HTML. Tampilan sesuai dengan gambar 7 diakses menggunakan browser google chorme, tampilan tersebut menampilkan 4 menu atau tombol utama, sebagai pengendali dari motor servo yang digunakan. Berikut penjelasan dari keempat tombol utama yang ditampilkan pada layout alat kendali motor servo.

\section{- LEFT}

Tombol yang memiliki nama LEFT, memiliki fungsi untuk menggerakkan motor servo bergerak ke kiri dengan sudut pergerakan $10^{\circ}$ ke kiri. Maka derajat pergerakan juga akan dimunculkan pada SERVO DEGREE, seberapa derajatkah servo sudah bergerak ke kiri dapat diketahui melalui SERVO DEGREE. Pada tampilan gambar 8 dapat diperhatikan setelah tombol LEFT diklik atau ditekan maka motor servo akan bergerak sebesar $10^{\circ}$, sebanyak 4 kali atau 4 kali ditekan tombol $L E F T$ dan pada tampilan juga terdapat indikator SERVO DEGREE yang menyatakan bahwa motor servo sudah bergerak sebesar $40^{\circ}$, itu dikarenakan posisi motor servo pada awalnya adalah $90^{\circ}$, apabila bergerak ke kiri maka sudut akan berkurang $10^{\circ}$, maka didapat sudut pergerakan posisi motor servo saat ini adalah $50^{\circ}$. Perhitungan sudut Pada tombol LEFT dapat menggunakan formula ini : Sudut Akhir = Sudut Awal - Sudut Pergerakan $=90^{\circ}-40^{\circ}=50^{\circ}$

\section{- $R I G H T$}

Tombol yang memiliki nama RIGHT, memiliki fungsi untuk menggerakkan motor servo bergerak ke kanan dengan sudut pergerakan $10^{\circ}$ ke kanan. Maka derajat pergerakan juga akan dimunculkan pada SERVO DEGREE, seberapa derajatkah servo sudah bergerak ke kanan dapat diketahui melalui SERVO DEGREE. Pada tampilan gambar 9 dapat diperhatikan setelah tombol RIGHT diklik atau ditekan maka motor servo akan bergerak sebesar $10^{\circ}$, sebanyak 6 kali atau 6 kali ditekan tombol RIGHT dan pada tampilan juga terdapat indikator SERVO DEGREE yang menyatakan bahwa motor servo sudah bergerak sebesar $150^{\circ}$, itu dikarenakan posisi motor servo pada awalnya adalah $90^{\circ}$, apabila bergerak kekanan maka sudut akan bertambah $10^{\circ}$, maka didapat sudut pergerakan posisi motor servo saat ini adalah $150^{\circ}$. Perhitungan sudut Pada tombol RIGHT dapat menggunakan formula ini : Sudut Akhir = Sudut Awal + Sudut Pergerakan $=90^{\circ}+60^{\circ}=150^{\circ}$ 


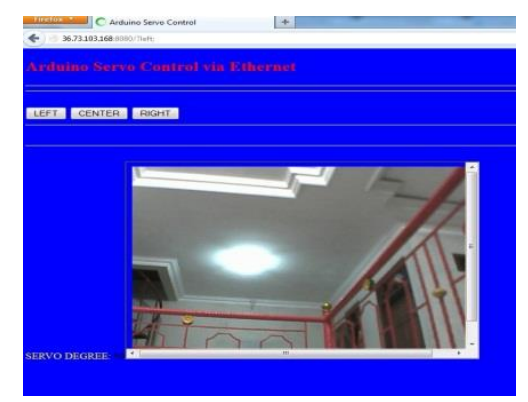

Gambar 6. Tampilan Layout Interface

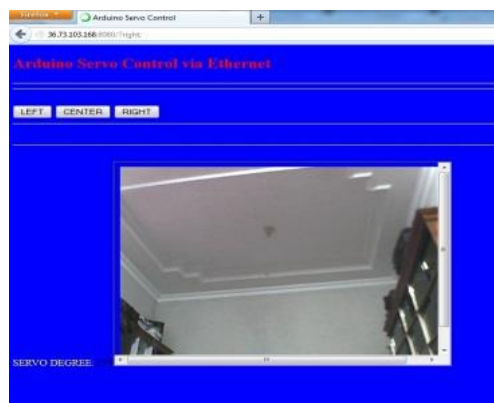

Gambar 7. Tampilan Layout Setelah DiKlik Tombol RIGHT

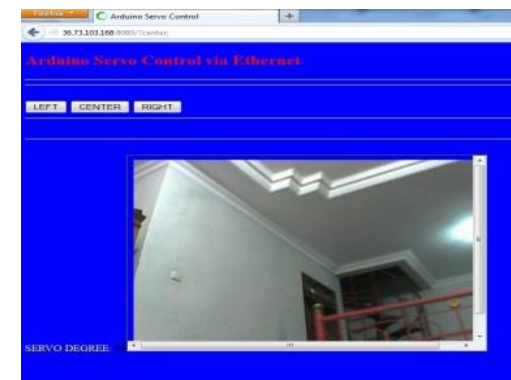

Gambar 8. Tampilan Layout Setelah DiKlik Tombol LEFT

\section{B. Hasil Pengujian Hardware}

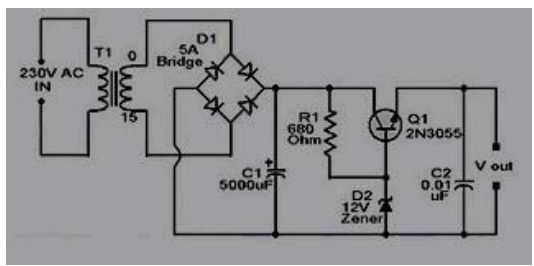

Gambar 9. Skematik Adaptor

Tabel 2. Pengujian Catu Daya

\begin{tabular}{|c|c|}
\hline Pengujian Alat & Tegangan \\
\hline $\begin{array}{c}\text { Catu Daya Adaptor } \\
\text { yang diharapkan }\end{array}$ & 12 Volt \\
\hline $\begin{array}{c}\text { Catu Daya Adaptor } \\
\text { hasil Pengujian }\end{array}$ & 12,96 Volt \\
\hline
\end{tabular}

Dalam pembuatan alat kendali motor servo digunakan catu daya yang berbentuk adaptor, dan mengambil tegangan AC dari PLN ( Perusahaan Listrik Negara ). Input tegangan yang diberikan PLN untuk adaptor ini adalah sebesar 220 Volt dan akan diubah oleh adaptor menjadi 12 Volt. Pengujian catu daya dilakukan dengan mengukur keluaran dari adaptor tersebut. Hasil pengujian dari keluaran adaptor didapat berupa 12,96 Volt sementara yang diharapkan pada pembuatan alat kendali motor servo ini adalah 12 Volt. Berikut tabel pengujian dari pengujian catu daya yang digunakan sesuai dengan gambar 10, dan11.

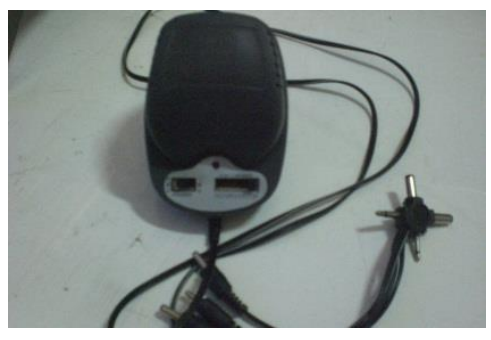

Gambar 10. Adaptor yang Digunakan

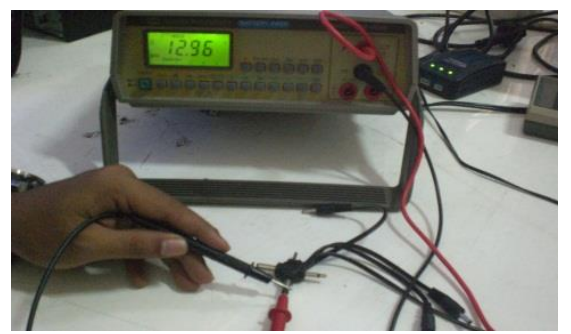

Gambar 11. Pengukuran Catu Daya Adaptor

Arduino Uno R3 merupakan papan mikrokontroler yang berdasarkan Atmega328. Arduino Uno R3 memiliki 14 pin digital input dan output, 6 pin input analog, $16 \mathrm{MHz}$ ceramic resonator, sebuah koneksi Universal Serial Bus, sebuah Power Jack, sebuah ICSP header, dan tombol reset. Sesuai dengan gambar 12 dan 13 pada saat melakukan pengukuran.

Tabel 3. Spesifikasi Arduino Uno R3

\begin{tabular}{|c|c|}
\hline Mikrokontroler & ATmega328 \\
\hline $\begin{array}{c}\text { Tegangan } \\
\text { pengoperasian }\end{array}$ & $5 \mathrm{~V}$ \\
\hline $\begin{array}{c}\text { Tegangan input yang } \\
\text { disarankan }\end{array}$ & $7-12 \mathrm{~V}$ \\
\hline Batas tegangan input & $6-20 \mathrm{~V}$ \\
\hline Jumlah pin I/O digital & $\begin{array}{c}14 \text { (6 di antaranya } \\
\text { menyediakan keluaran PWM) }\end{array}$ \\
\hline $\begin{array}{c}\text { Jumlah pin input } \\
\text { analog }\end{array}$ & 6 \\
\hline Arus DC tiap pin I/O & 50 mA \\
\hline $\begin{array}{c}\text { Arus DC untuk pin } \\
3.3 \mathrm{~V}\end{array}$ & $\begin{array}{c}32 \mathrm{~KB} \text { (ATmega328), sekitar } \\
0.5 \mathrm{~KB} \text { digunakan oleh } \\
\text { bootloader }\end{array}$ \\
\hline Memori Flash & 2 KB (ATmega328) \\
\hline SRAM & $1 \mathrm{~KB}$ (ATmega328) \\
\hline EEPROM
\end{tabular}




\begin{tabular}{|c|c|}
\hline Mikrokontroler & ATmega328 \\
\hline Clock Speed & $16 \mathrm{MHz}$ \\
\hline
\end{tabular}

Tabel 4. Hasil Pengujian Arduino Uno R3

\begin{tabular}{|c|c|c|}
\hline Perangkat & \multicolumn{2}{|c|}{ Tegangan } \\
\hline \multirow{2}{*}{ Arduino Uno R3 } & Vin & Vout \\
\cline { 2 - 3 } & 12,96 Volt & 4,99 Volt \\
\hline
\end{tabular}

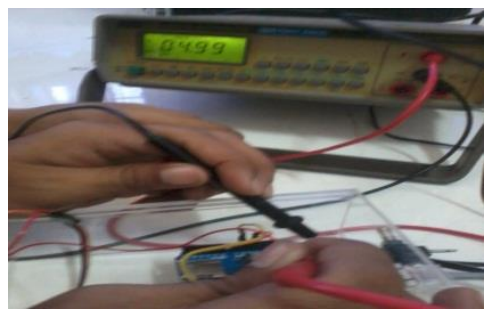

Gambar 12. Pengujian Arduino Uno R3

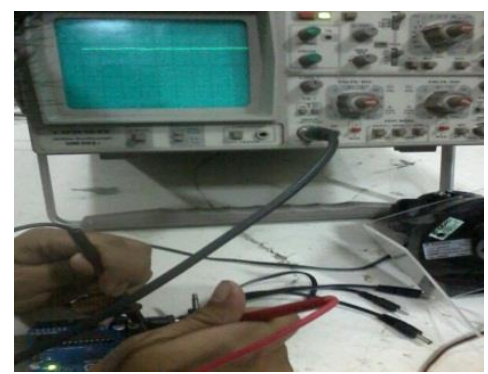

Gambar 13. Pegujian Arduino Uno R3 dengan Osiloskop Analog

Arduino Ethernet Shields merupakan modul arduino yang memungkinkan arduino terhubung dengan internet menjadi sebuah web server atau berkomunikasi dengan perangkat lainnya yang terhubung dengan jaringan. Sesuai dengan gambar 14 dan 15 pada saat melakukan pengukuran.

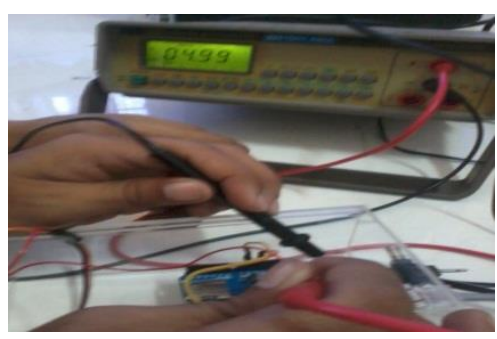

Gambar 14. Pengujian Arduino Ethernet Shields

Tabel 5. Hasil Pengujian Arduino Ethernet Shield

\begin{tabular}{|c|c|c|}
\hline \multirow{2}{*}{ Perangkat } & \multicolumn{2}{|c|}{ Tegangan } \\
\hline \multirow{2}{*}{$\begin{array}{c}\text { Arduino Ethernet } \\
\text { Shield }\end{array}$} & Vin & Vout \\
\cline { 2 - 3 } & 4,99 Volt & 4,99 Volt \\
\hline
\end{tabular}

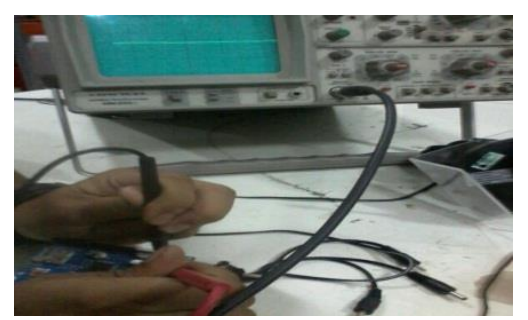

Gambar 15. Pengujian Arduino Ethernet Shield dengan Osiloskop Analog

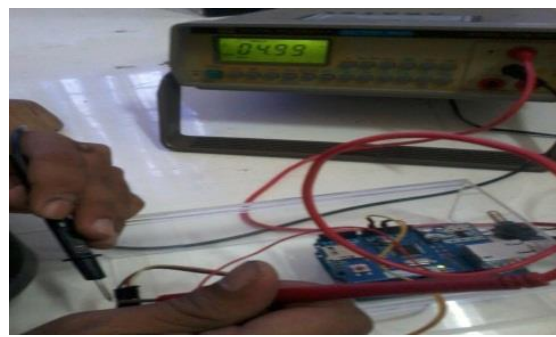

Gambar 16. Pengujian Motor Servo

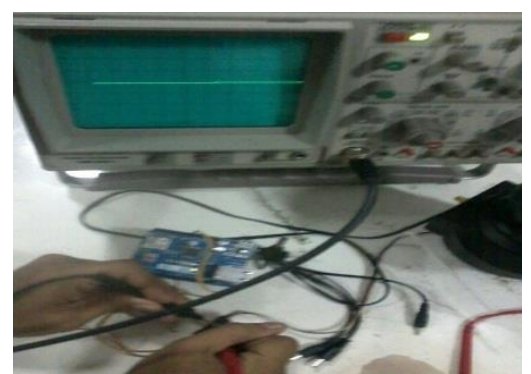

Gambar 17. Pengujian Motor Servo dengan Osiloskop Analog

Dari gambar 16 dan 17 dapat disimpulkan untuk dapat menggerakan Motor Servo diperlukan rangkaian yang memiliki mikrokontroler dan memiliki script pemrograman untuk menggerakkan motor servo tersebut. Dalam melakukan pergerakan motor servo mendapatkan berbagai sinyal yang memiliki lebar pulsa yang berbeda beda yang dikirim selama periode waktu tertentu dan teratur, maka servo akan bergerak sesuai dengan sinyal tersebut

\section{KESIMPULAN DAN SARAN}

\section{A. Kesimpulan}

Berdasarkan hasil Peragkaian dan Pengujian dari alat kendali motor servo ini dapat diambil beberapa kesimpulan diantaranya adalah :

1. Alat Kendali Motor Servo ini dapat bekerja dengan baik sesuai dengan tujuan penulisan

2. Alat Kendali Motor Servo ini dapat dikendalikan melalui Internet dengan memanfaatkan fasilitas NAT

3. Penulis Menggunakan Acces Point milik PT. Telkom Indonesia ataupun Telkom Speedy

4. Dalam menghubungkan alat kendali motor servo ke internet penulis memanfaatkan IP Publik yang disediakan oleh penyedia layanan 
internet yang diberikan karena berlangganan dengan penyedia layanan internet tersebut

5. IP Publik yang diberikan oleh penyedia layanan internet ataupun telkom speedy merupakan IP Publik yang berjenis Dinamis.

B. Saran

Saran-saran untuk pengembangan penelitian ini agar dapat dimaksimalkan lebih lanjut adalah:

1. Dikarenakan alat kendali motor servo ini masih bersifat prototype, masih perlu dilakukan perbaikan terhadap bentuk dan tempat dari alat kendali motor servo.

2. Untuk pengembangan selanjutnya, alat kendali motor servo dapat diaplikasikan terhadap IP Publik yang bersifat Statis, agar tidak terjadi kesalahan pada saat akan mengakses alamat alat kendali motor servo ini.

3. Untuk pengembangan selanjutnya, perlu ditambahkan pengaman terhadap web yang digunakan sebagai interface pada alat kendali motor servo.

4. Untuk pengembangan selanjutnya, perlu dilakukan pengujian terhadap perangkat nirkabel lainnya seperti tablet $P C$ maupun Handphone dalam mengakses alamat alat kendali motor servo.

5. Untuk pengembangan selanjutnya, perlu ditambahkan satu menu yang berkonsep kontrol untuk menentukan pengaturan derajat pada motor servo.

\section{REFERENSI}

[1] Arduino. (t.thn.). Dipetik April 24, 2013, dari http://www.arduino.cc

[2] Compaq Intel Microsoft NEC. (1998) Universal Serial Bus Spesification

[3] Djuandi, F. (2011, July). Pengenalan Arduino.

[4] Eka Syahputra Harahap, S. S. (2009). Algoritma Pemrograman. Medan.

[5] Evans, B. (2011). Beginning Arduino Programming. New York: Springer

Science+Business Media.

[6] GWS USA. (2006). GWS Servo and Accescories.

[7] Karim, W. S. (2012). Pemrograman Dengan Web.

[8] McRoberts, M. (2010). Beginning Arduino. New York: Springe Science+Business Media.

[9] Raharjo, I. M. (2008). Pemrograman $C$ dan Implementasinya. Bandung: Informatika Bandung.

[10] Setting up Arduino Webserver for remote access. (t.thn.). Dipetik 07 24, 2013, dari Arduino: Setting up Arduino Webserver for remote access - ArduinoForum.htm

[11] SunBio. (t.thn.). IP Camera User Manual .

[12] tp-link.co.id. (n.d.). Retrieved Juni 11, 2013, from www.tp-link.co.id 